\title{
PRIMARY OSTEOPOROSIS MANAGEMENT BY THE MARCHE REGION HEALTH CARE SYSTEM
}

\author{
Dott.ssa David Letizia ${ }^{1}$, Prof.ssa Ceravolo Maria Gabriella ${ }^{2}$, Dott. Mengoni Alessandro ${ }^{3}$ \\ Asur Marche - Area Vasta 3 \\ ${ }^{2}$ Università Politecnica delle Marche - Ospedali Riuniti Ancona \\ ${ }^{3}$ Regione Marche
}

KEYWORDS: Osteoporosis, risk of fall, fragility fractures, rehabilitation, pathway, empowerment

\section{ABSTRACT}

Osteoporosis is an illness that affects the skeleton and is characterized by progressive loss of bone mass as well as by micro architectural deterioration of bone tissue of the same. This condition exposes the person to fracture risk, a particularly feared event not only in terms of individual health but even in terms of economic burden. The fractures, in fact, are accompanied by autonomy loss, institutionalization risk, comorbidity and mortality. On an economic level, the reduction of the same absorbs many more resources than anti-osteoporosis drug therapies even in the event that all patients are reached with ascertained osteoporosis and with $100 \%$ adherence to medication. In the elderly, in addition to incurring in loss of bone density risk there is an increase of fall risk. Both of these factors add up causing an increase of fracture risk. Due to the demographic increase and life expectancy, osteoporosis and fracturing events will tend to increase, causing an increase in costs. Today, the data collected in Italy regarding osteoporosis prevalence and fragility fractures incidences are not entirely exhaustive. Concerning fractures, data is reliably collected using the "Diagnosis Related Group Classification" and refers to those of the femur.

Detect and describe the pathway that the patient with primary osteoporosis follows in the Marche Region.

Through the regional Single Booking Center (CUP) and the websites of the Italian League of Osteoporosis (LIOS) and the Italian Society of Osteoporosis, Mineral Metabolism and Skeleton Diseases (SIOMMMS), eleven services have been identified, belonging to the four health care companies of the Marche Region (Asur, Inrca-Irccs, AO Ospedali Riuniti Marche Nord, AOU Ospedali Riuniti Ancona), which can be contacted for an osteoporosis checkup. A questionnaire was therefore prepared based on the recommendations contained in the SIOMMMS (2012), SIMFER and SIGN (2015) guidelines and sent to the above-mentioned services. The questionnaires are seven, duly completed and used for processing data.

In the Marche Region, the medical specialties that deal with osteoporosis are various, demonstrating the fact that this is a "border illness". Concerning the interception of the patient, his sending to a specialized service, the diagnostic approach and the use of risk-scoring tools, there is a substantial homogeneity throughout the regional territory. The patient is sent to the specialized center by the general practitioner (GP) or other specialist, based on the presence of risk factors for osteoporosis alone or on the basis of their presence in association with BMD measurement (body mass density measurement) already known. For the purposes of diagnosis, the investigations required are the dual-energy $x$-ray absorptiometry (DXA) and the blood test while the use of risk-scoring tools are mainly dictated by the need to define the threshold of pharmacological intervention and give the patient perception of its own fracture risk. The most used algorithm is DeFRA. During the evaluation of the patient, all services detect pain and fall risk.

The approach to osteoporosis and fall risk is purely pharmacological. From a non-pharmacological point of view, attention is paid in informing the patient about the modifiable risk factors for osteoporosis and falls. Only some services carry out interventions aimed at promoting adherence to treatment, resorting to different actions. In conclusion, the main critical issues relating to taking care of a fracture risk patient are: accessibility to information, early and exhaustive interception of the population at risk, detection of the fracture risk in relation to bone demineralization and fall risk, adherence to therapy.

\section{INTRODUCTION}

Osteoporosis is defined as a syndrome associated with low bone mass and micro architectural deterioration of bone tissue that leads to an increased fracture risk. It is an illness linked to old age, chronic and silent. Clinically, it gives no particular signs or symptoms until fractures occur, with important repercussions on individual health and social costs. Fractures, particularly those of the femur, are accompanied by autonomy loss, institutionalization risk, comorbidity and mortality. Due to the demographic increase and the increase in life expectancy, osteoporosis and fracturing events will register an increasing incidence, with a relative increase in health expenditure. Today data on fractures collected in Italy are not entirely exhaustive.
The most reliable data relates to femur fractures since they are counted by means of the Hospital Discharge Cards (SDO) requesting treatment in a hospital. Figure 1 .

Table 1 reports the number of hospitalizations for femur fractures that occurred in the Marche Region in 2013. The reference population is represented by residents of the Marche Region over 65 years of age and according to the International Classification of Diseases (ICD-9) they have the following diagnosis codes: 820.XX (Femoral neck fracture), 821.XX (Fracture of other and unspecified parts of the femur), 829.XX (Fractures of unspecified bones), 733.14 (Pathological fracture of the femoral neck) and 733.15 (Patho- 


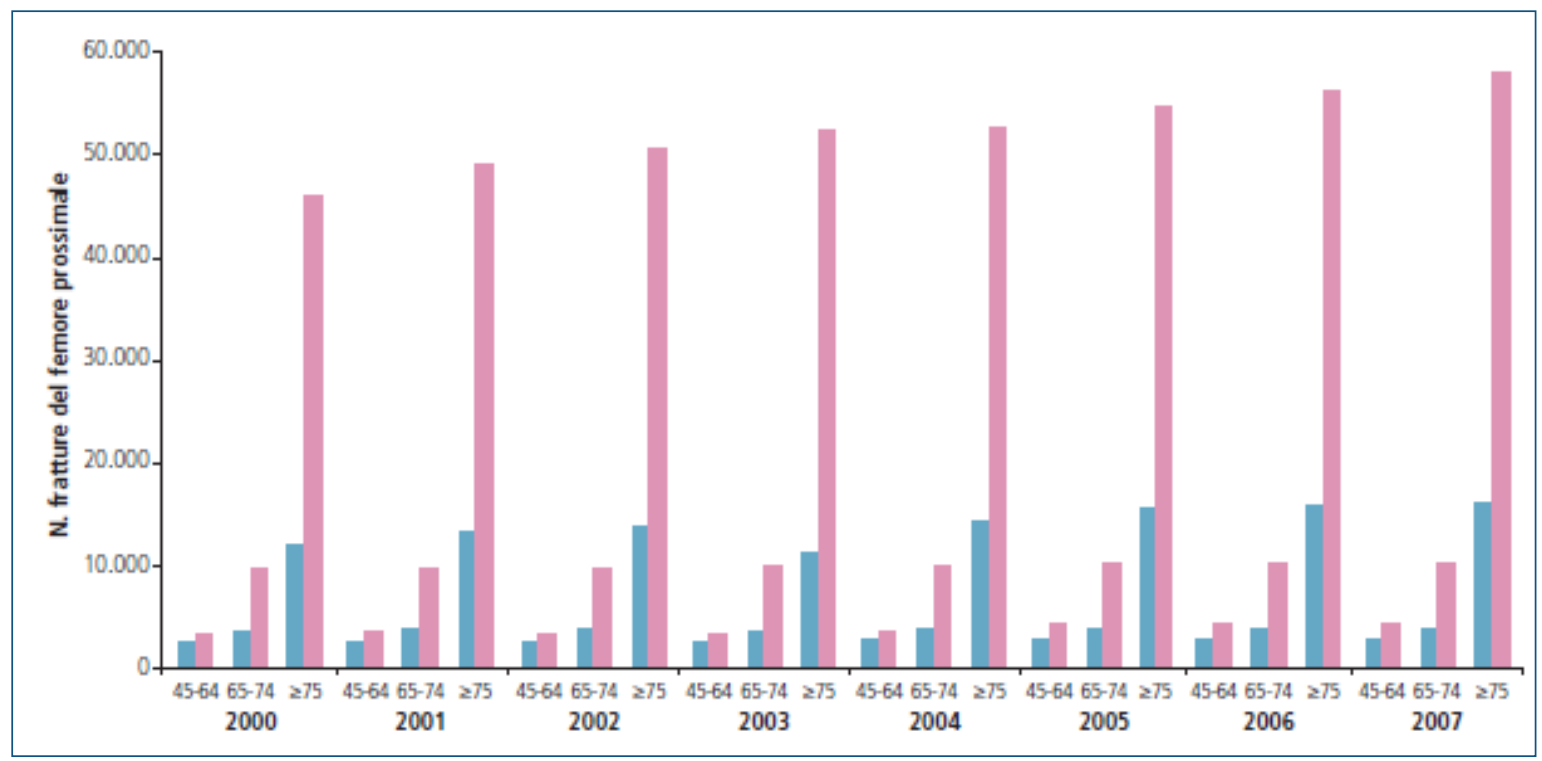

Fig. 1 - Annual incidence of femoral fractures from 2000 to 2007 in the italian male (blue) and female population (pink) over the age of 45. SDO data. Source "Health Papers. Diagnostic and therapeutic appropriateness in the prevention of fragility fractures “. Ministry of Health, 2010.

logical fracture of other specified parts of the femur). Data, divided by gender and age classes, report the days of hospital stay and the relative costs. The last column calculates the incidence of femoral fracture hospitalizations every 10,000 inhabitants.

The regional trend confirms the national trend: femoral fractures significantly affect females and grows with the increasing of age. Women over the age of 85 represent the most risky class. In all age groups (except ages 65-69), women have a fracture risk 3 times more than men do. In 2013, about 82 people every 10,000 inhabitants were affected by a femur fracture. In particular, in the most risky age group, which is over 85 , there are 280 women/10,000 inhabitants compared to $197 \mathrm{men} / 10,000$ inhabitants (2.8 women/100 inhabitants and $1.9 \mathrm{men} / 100$ inhabitants). In the same year, 2,922 femoral fracture operations were performed in the Marche Region on elderly over 65 with an average length of hospital stay of 13.7 days. In fact, it goes from a 12.3-day stay for women between 65-69 to a 15.3-day stay for men between 75-79 and 80-84. In 2013, the costs attributable to surgical management of fractures and post-operative care amounted to $€ 20,388,678$. Dividing this sum by the number of hospitalizations in the same year $(2,922)$, we obtain what the Marche Region has spent an average of $€ 7,000$ for the surgical reduction of a femur fracture. In this phase, direct health costs also include expenses attributable to rehabilitation treatment. Assuming that the duration of hospitalization in an intensive rehabilitation care unit is 25 days and considering a daily allowance of $€ 300$, you can easily calculate the expense attributable to rehabilitation alone: $€ 7,500$ for every patient. Adding to this figure the one calculated previously, it is possible to say that, in the first month and a half after the fracture, the Regional Health System is incurring an expense of $€$ 14,500 for every patient.

An Italian study has also recently shown that surgical reduction of fragility fractures (on the over 65) absorbs many more resources than anti-osteoporosis drug therapies. This is also the case in which all patients with proven osteoporosis and adherence to therapy are one hundred percent reached. The authors conducted

\begin{tabular}{|c|c|c|c|c|c|c|}
\hline Gender & Age classes & Hospital stay & $\begin{array}{c}\text { Days of } \\
\text { hopital stay }\end{array}$ & Costs $(€)$ & $\begin{array}{l}\text { Residents of the } \\
\text { Marche Region } \\
\text { in } 2013\end{array}$ & $\begin{array}{l}\text { Incidence of femoral } \\
\text { fracture hospitaliza- } \\
\text { tions every } 10,000 \\
\text { inhabitants }\end{array}$ \\
\hline \multirow{5}{*}{ Male } & $65-69$ & 33 & 443 & 214.087 & 40.209 & 8,2 \\
\hline & $70-74$ & 62 & 808 & 416.733 & 38.042 & 16,3 \\
\hline & $75-79$ & 110 & 1.685 & 824.599 & 32.367 & 34,0 \\
\hline & $80-84$ & 154 & 2.358 & 1.229 .246 & 23.457 & 65,7 \\
\hline & +85 & 368 & 5.084 & 2.560 .418 & 18.697 & 196,8 \\
\hline \multirow{5}{*}{ Female } & $65-69$ & 74 & 912 & 502.701 & 43.796 & 16,9 \\
\hline & $70-74$ & 180 & 2.477 & 1.273 .577 & 44.381 & 40,6 \\
\hline & $75-79$ & 348 & 4.558 & 2.402 .468 & 41.189 & 84,5 \\
\hline & $80-84$ & 480 & 6.570 & 3.420 .472 & 34.851 & 137,7 \\
\hline & +85 & 1.113 & 15.273 & 7.544 .375 & 39.646 & 280,7 \\
\hline TOTAL & & 2.922 & 40.168 & 20.388 .678 & 356.635 & 81,9 \\
\hline
\end{tabular}

Tab. 1 - Incidence and costs of femur fractures in over 65 year olds people residing in the Marche region. Summary table. 

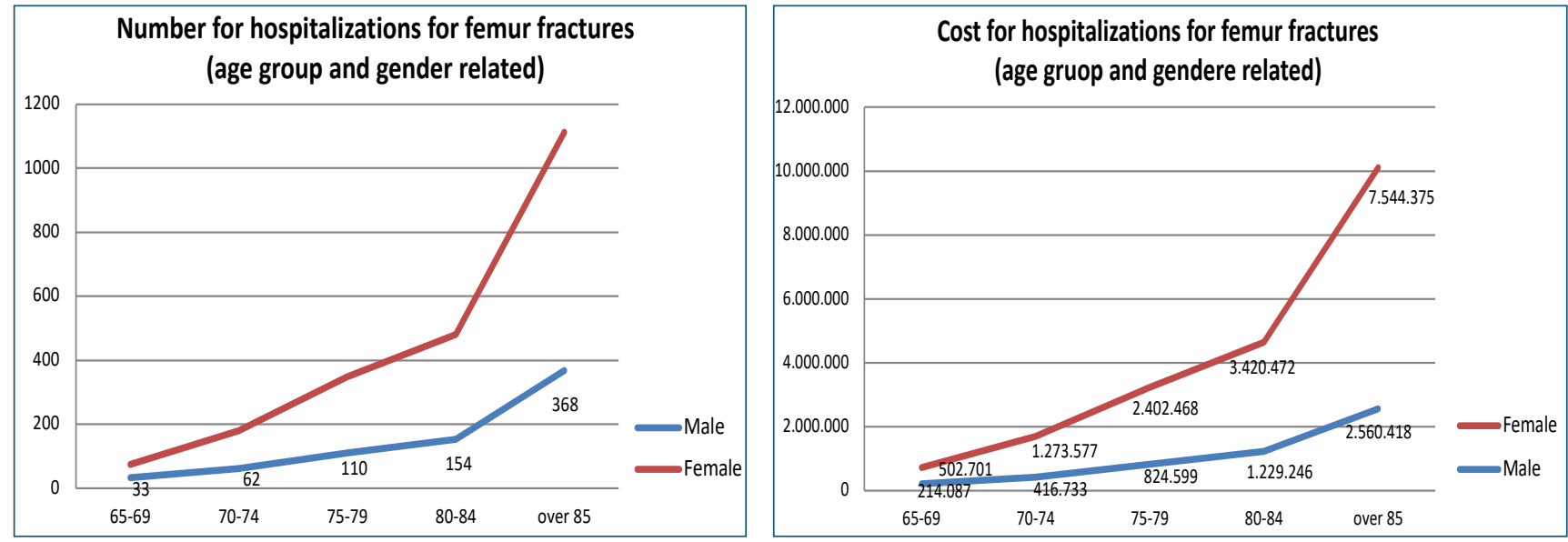

Fig. 2 e 3

this survey starting from real data and related to the Tuscany Region where about $13.1 \%$ of the patients operated for femur fracture follow a pharmacological treatment with bisphosphonate, calcium and vitamin D and have an adherence to the treatment equal to $40 \%$. The cost of drug therapy affects $0.3 \%$ on direct health costs for the treatment of femoral fractures. Table 2. Simulating, moreover, that all patients with femur fracture should undergo anti-fracture therapy with an adherence of $100 \%$ in one year, the expenditure would rise considerably (from $€ 1,645,875$ to $€ 17,949,500$ ) but would still represent $1,8 \%$ of the direct costs for the treatment of femoral fractures and $0.18 \%$ of the total pharmaceutical expenditure. Table 3.

The authors therefore stress the importance of initiating adequate anti-fracture therapy in all subjects affected by previous fragility fractures and adopting strategies to improve adherence to treatment, in order to obtain a therapeutic effect, to contain adverse events and to reduce costs. Even AIFA (Italian Medicines Agency) calls for a containment of occasional consumption of these drugs and carefully select those who can really benefit from them. In light of the above, it is therefore appropriate to identify early those at risk of bone demineralization and to start effective treatment in order to prevent the appearance of the much feared fractures, attributable not only to skeletal fragility but also to the increased fall risk found in the elderly population. Indeed, osteoporosis and fall risks contribute independently to determine fracture risk. The aim of the study is to conduct a fact-finding investigation in order to trace the current clinical pathway that the patient with primary osteoporosis follows in the Marche Region.

\section{METHODS}

A search was carried out through the websites of the various local health companies and hospitals in the Marche Region to search published and consultable clinical pathways on primary osteoporosis but there were no results. Therefore. eleven services have been identified through the regional Single Booking Center

\begin{tabular}{lcccccc}
\hline & Year 2000 & Year 2001 & Year 2002 & Year 2003 & Year 2004 & Year 2005 \\
\hline Hospitalizations due to hip fractures & 73493 & 78354 & 80804 & 89796 & 90753 & 94471 \\
Expected hip fractured patients $>65$ & 58794 & 62683 & 64643 & 71837 & 72602 & 75577 \\
Overall hospitalizations direct costs & $343,000,000$ & $373,000,000$ & $394,000,000$ & $433,000,000$ & $448,000,000$ & $467,500,000$ \\
Overall rehabilitation costs $€$ & $392,876,272$ & $418,852,367$ & $431,970,539$ & $480,005,732$ & $485,140,236$ & $531,986,400$ \\
Costs of the therapies $€ \wedge$ & $1,280,300$ & $1,365,000$ & $1,407,875$ & $1,564,500$ & $1,581,125$ & $1,645,875$ \\
Total estimated costs $€$ & $738,436,872$ & $794,582,367$ & $828,786,289$ & $916,134,732$ & $936,302,486$ & $1,002,778,150$
\end{tabular}

Tab. 2 - Direct costs incurred for the treatment of femoral fractures, drug therapy and rehabilitation in people $>65$ years old, during 2000-2005. Fractures occurred in people under 65 years old are excluded, as they cannot be classified as fragility fractures.

\begin{tabular}{lcccccc}
\hline & Year 2000 & Year 2001 & Year 2002 & Year 2003 & Year 2004 & Year 2005 \\
\hline Hospitalizations due to hip fractures $>65$ & 73493 & 78354 & 80804 & 89796 & 90753 & 94471 \\
Expected hip fractured patients $>65($ no.) & 58794 & 62683 & 64643 & 71837 & 72602 & 75577 \\
Pts (no.) discharged from the hospital $^{*}$ & 55854 & 59549 & 61411 & 68245 & 68972 & 71798 \\
Costs of the therapies (Euros) $^{\wedge}$ & $13,963,500$ & $14,887,250$ & $15,352,750$ & $17,061,250$ & $17,243,000$ & $17,949,500$ \\
\hline
\end{tabular}

Tab. 3 - Simulation of drug costs in subjects $>65$ years old, simulating that all patients should undergo anti-fracture therapy with an adherence of $100 \%$ in one year. Fractures that occur in subjects under 65 are excluded, as they cannot be classified as fragility fractures. 


\section{Which medical specialities are referred to by the single service dedicated to the treatment of osteoporosis?}

\author{
- Rheumatology \\ - Geriatrics \\ - Physical Medicine and Rehabilitation \\ Endocrinology \\ Diabetology
}

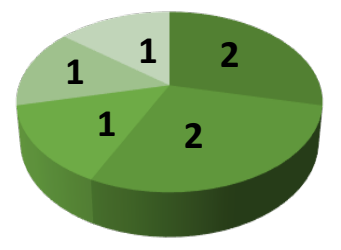

Fig. 4

(CUP) and the websites of the Italian League of Osteoporosis (LIOS) and the Italian Society of Osteoporosis, Mineral Metabolism and Skeleton Diseases (SIOMMMS), belonging to the four health care companies of the Marche Region (Asur, Inrca-Irccs, AO Ospedali Riuniti Marche Nord, AOU Ospedali Riuniti Ancona), which can be contacted for an osteoporosis checkup. Three of these services are located in the province of Ancona, two in the province of Pesaro-Urbino, three in the province of Macerata, two in the province of Ascoli Piceno and one in the Fermo area. A questionnaire was therefore drawn up, consisting of 5 closed dichotomous questions and 12 closed multiple choice questions, prepared on the basis of the recommendations contained in the SIOMMMS (2012), SIMFER and SIGN (2015) guidelines. The questionnaire was developed in order to investigate: who and how the patient with primary osteoporosis intercepts, what type of instrumental tests are conducted for diagnostic purposes, what are the proposed treatments, how therapeutic monitoring is conducted and if any, what are the advanced strategies that improve adherence to treatment.

\section{RESULTS AND DISCUSSIONS}

The first question is aimed at understanding which medical specialties are referred to by the single service dedicated to the treatment of osteoporosis.
The most represented specialties are Geriatrics and Rheumatology, each present in two out of seven services, followed by Endocrinology, Physical Medicine and Rehabilitation and Diabetology. Osteoporosis is a "borderline illness" and the specialists who deal with it are from different backgrounds. This represents, on one hand, a strength, as continuous exchanges and comparisons are possible but, on the other, it could generate differences in the approach to the illness. This difficulty was recognized by SIOMMMS itself that gave birth to the Bone Project (2015). This project is oriented to specialists and general practitioners (GPs) and it is promoted with the aim of overcoming the problem of therapeutic appropriateness and giving the intervention a national uniformity, which exceeds the individual medical specialties and the respective training. The fact that various specialties deal with bone diseases could also be a confusing element for citizens. Hence, the role of the GP is fundamental in order to direct patients to the most suitable service. It is also equally important to improve the accessibility of information in order to sensitize the population at risk, guarantee them greater autonomy and facilitate access to services.

Questions 2 and 3 investigate how the patient with osteoporosis accesses the specialist service. All services assert that patient is sent by the GP or another specialist doctor. In two cases, the response "sent through screening campaigns" was also selected.

The patient is sent to the specialist service if there are risk factors for osteoporosis (4 out of 7 cases) or based on their presence in association with the already known diagnostic data (4 out of 7 cases). It, therefore, appears that the mere presence of risk factors for osteoporosis is a sufficient condition to request a specialist consultation, even in the absence of an instrumental examination that justifies a situation of bone demineralization. The subsequent questions have been elaborated in order to define how the patient evaluation takes place. For the purposes of diagnosis, the investigations always required are bone densitometry with dual-energy x-ray absorptiometry (DXA) and blood tests (7 cases out of 7). In four services, vertebral morphometry is also used and in two services, the dosage of biochemical bone turn over markers is used. In only one case, the evaluation of the Trabecular Bone Score (TBS) is carried out and Quantitative Computed Tomography (QCT) is occasionally prescribed.

As the guidelines suggest, bone densitometry with DXA technique is the technique of choice in the evalu-

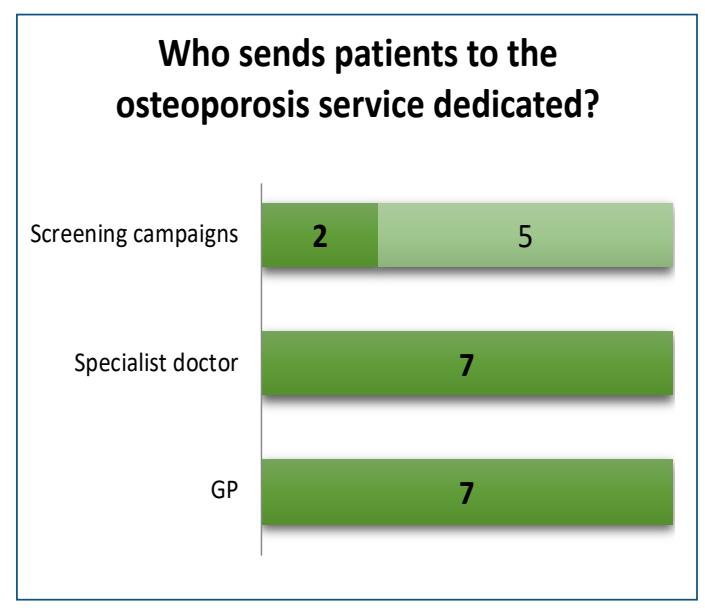

\section{How do patients with osteoporosis access the specialist service?}

\begin{tabular}{|c|c|c|}
\hline $\begin{array}{l}\text { Risk fractures ascertained by fractures tools + } \\
\text { diagnostic data }\end{array}$ & 1 & 6 \\
\hline Risk factors ascertained by fractures tools & 1 & 6 \\
\hline Risk factors for osteoporosis + diagnostic data & 4 & 3 \\
\hline Risk factors for osteoporosis & 4 & 3 \\
\hline
\end{tabular}




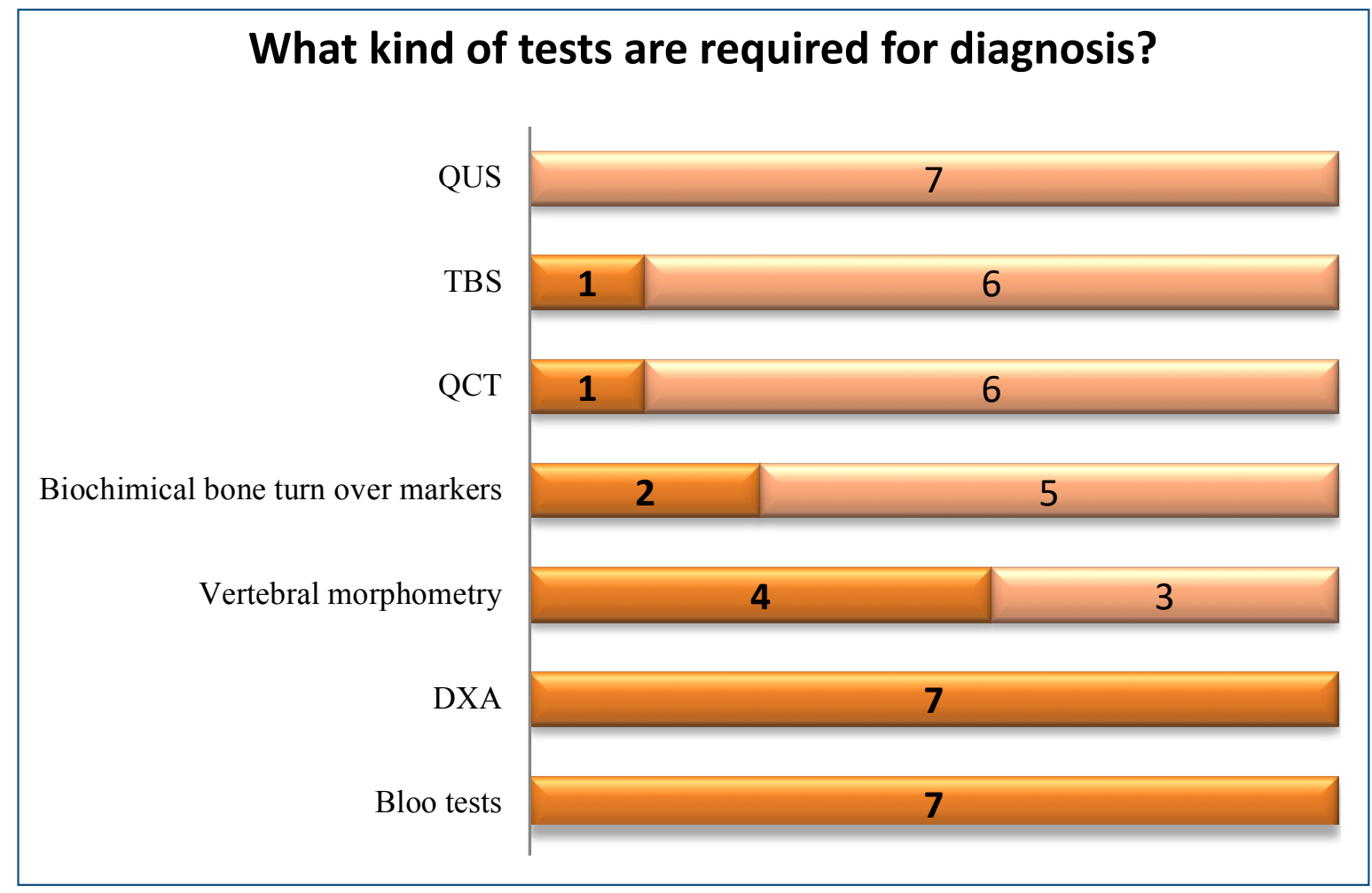

Fig. 7

ation of bone mass, while blood chemistry tests allow carrying out the differential diagnosis between primary and secondary osteoporosis. Therefore, they are both fundamental investigations for a correct diagnostic approach which is shared by all services. Other diagnostic investigations, such as vertebral morphometry, QTC and the evaluation of the TBS are presumably justified in case of specific diagnostic doubts. The choice to carry out the dosage of the biochemical markers of bone turn over does not appear, however, justified by the guidelines, both for the high costs and for the poor reproducibility of the results. The quantitative ultrasound parameter (QUS) option has never been selected. QUS has a good predictability index, which is also independent from bone densitometry, but is not accepted for diagnostic purposes according to WHO criteria.

The use of fracture risk algorithms is widespread (6 out of 7 cases). The best known is DeFRA, which is used by 6 services out of 7 and in two cases it is associated with FRAX. Risk algorithms are used to define the pharmacological intervention threshold ( 5 cases out of 7), to give the patient a perception of their fracture risk ( 5 cases out of 7), to identify patients to undergo a diagnostic investigation ( 2 services out of 7 ) and to decide whether to change the pharmacological intervention threshold over time ( 2 services out of 7$)$. This reflects what is suggested by the SIOMMMS guidelines that hope for a greater diffusion of these algorithms. Furthermore, clinicians attribute to FRAX and DeFRA an informative-communicative validity as they use it to give perception to the patient's own fracture risk. In particular, they recognize the validity of DeFRA that was developed by SIOMMMS itself in collaboration with SIR (Italian Society of Rheumatology).

In the evaluation phase, all services record the presence/extent of pain and fall risk.

Questions 8, 9, 12 and 13 investigate what the therapeutic strategies are used, with particular attention to those of non-pharmacological treatment. A widespread action is to inform the patient about modifiable

\section{Are fractures risk algorithms used in clinical practice?}

- Yes $\square$ Not

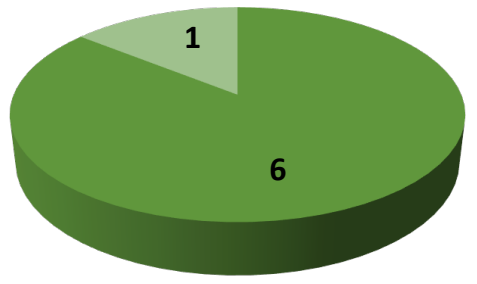

\section{Why are fractures risk algoritmics used for?}

To decide whether to change the pharmacological intervention threshold over time

To identify patients to undergo a diagnostic investigation

To give the patient a perception of their fracture risk

To define the pharmacological intervention threshold

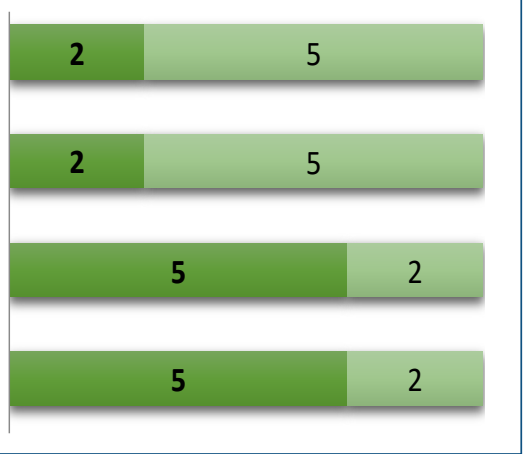




\section{What therapeutic strategies are provided by the services for the treatment of osteoporosis?}

APA to increase/maintain BMD with nonhealthcare personnel

Rehabilitation treatment to increase/maintain BMD with healthcare professionals

Post-fracture rehabilitation treatment

Formulation of pharmacological therapeutic plan

Formulation of diagnosis

To inform the patient

Fig. 10

risk factors for the prevention of osteoporosis and fragility fractures ( 7 cases out of 7 ), followed by the formulation of the diagnosis and the pharmacological therapeutic plan ( 6 cases out of 7 ), from post-fracture rehabilitation treatment ( 3 cases out of 7 ), from rehabilitation treatment to increase/maintain BMD with healthcare professionals ( 2 cases out of 7 ) and adapted physical activity (APA) to increase/maintain BMD with non-healthcare personnel (1 case out of 7).

The above data shows that the approach to osteoporosis is distinctly pharmacological. From a non-pharmacological point of view, the intervention mainly takes the form of correct information on modifiable risk factors. This aspect, having been selected from all the services, represents a moment of fundamental importance for clinicians. The rehabilitation intervention
1

2

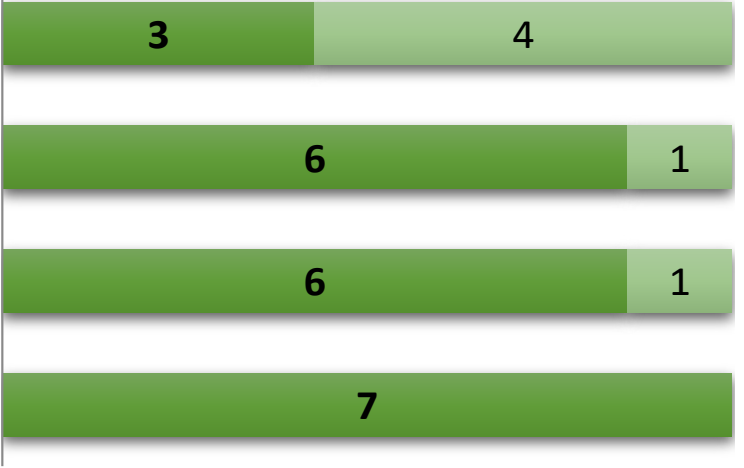

conducted by health personnel and aimed at increasing/maintaining the BMD, is expected by 2 services out of 7. It should be emphasized that these are services that refer, in one case, to Physical Medicine and Rehabilitation and, in the other, Rheumatology; therefore services that are born with a dedicated approach. In one service, Adapted Physical Activity (APA) is provided to increase/maintain BMD, conducted by non-physician personnel. Finally, 3 services provide rehabilitation treatment at the time of post-fracture.

It was therefore asked about which modifiable risk factors patients were informed on and what types of activities were provided to reduce the falling risk. From all services ( 7 out of 7) it is suggested to abolish smoking, limit alcoholic beverages, follow a balanced diet with adequate intake of calcium and vitamin D

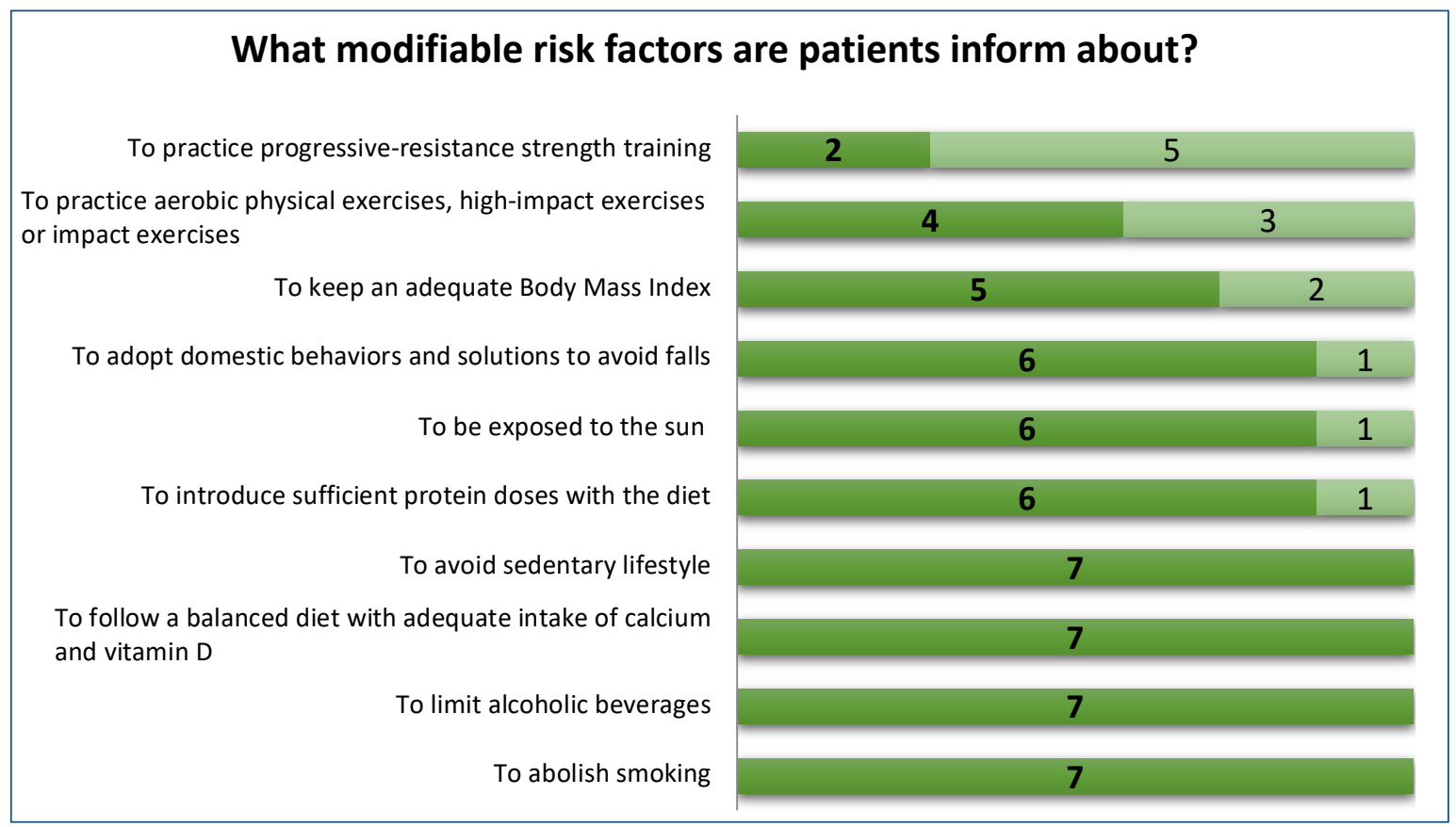




\section{What interventions are provided to reduce the risk of falling?}

Mobility aids for getting around and/or fall safe hip
protectors

Rehabilitation interventions to reduce falls

To estimare the risk of fall at home

To inform the patient of what are the modifiable risk factors

Prescription of vitamin D

Revision of drug therapy

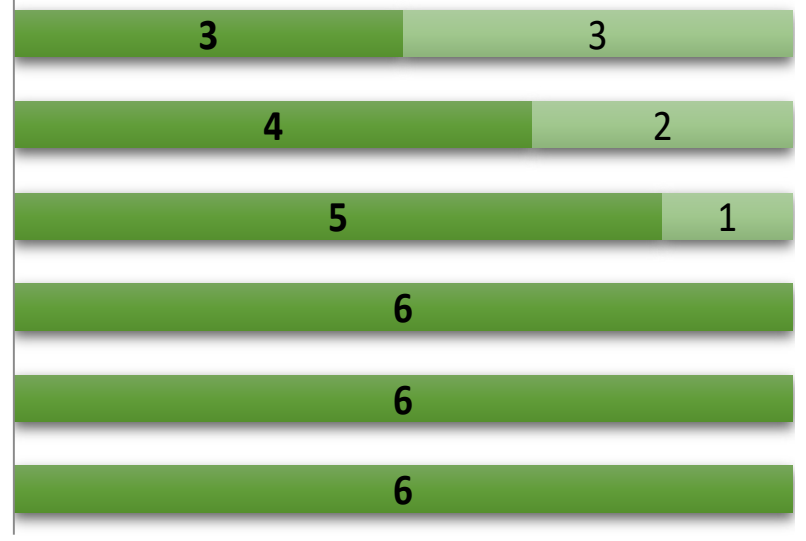

Fig. 12

and avoid sedentary lifestyle. From 6 out of 7 services, it is recommended to introduce sufficient protein doses with the diet, to be exposed to the sun and to adopt domestic behaviors and solutions to avoid falls. Five services recommend keeping an adequate Body Mass Index, 4 suggest to practice aerobic physical exercises, high-impact exercises or impact exercises and 1 to practice progressive-resistance strength training. This shows that the information transmitted to the patient with osteoporosis is exhaustive and takes place in compliance with the recommendations contained in the guidelines. However, one could insist more on the effectiveness of physical activity against bone mineralization, inviting patients to perform aerobic activity (such as brisk walking and applying small weights to the wrists) and strength resistance activities (such as muscle strengthening).

In 6 services out of 7, interventions aimed at fall prevention are carried out, such as the revision of drug therapy, the prescription of vitamin D and the communication to the patient of what are the modifiable risk factors ( 6 cases out of 7). In 5 services, the risk assessment is carried out at home, in 4 rehabilitation interventions are provided to reduce falls and in 3 , if worthwhile, mobility aids for getting around and/or fall safe hip protectors are recommended.

Even in this case, if the patient is carefully informed, the approach to contain the falling risk remains purely pharmacological (review of drugs and prescription of Vitamin D).

Questions 14 and 15 concern therapeutic monitoring. In this case, the examination required by all services (7 out of 7) is the bone densitometry assessed with the DXA technique that is repeated, generally, between 1 and 2 years ( 6 cases out of 7).In this case, the examination required by all services (7 out of 7) is the bone densitometry assessed with the DXA technique that is repeated, generally, between 1 and 2 years (6 cases out of 7). In one service over 2 years. Exactly as the guidelines recommend, the use of dual-energy x-ray absorptiometry DXA is the main exam to document bone mass density changes (BMD) and to monitor the results of drug therapy. The repetition of this investigation is justified after one year for spine densitometry, within one and a half/two years for hip densitometry and within two years for densitometry in other bones. Therefore, the response provided by the various services falls fully within the time range indicated in the guidelines.

The last part of the questionnaire investigates the presence of useful strategies to improve adherence to treatment (questions 16 and 17). These strategies are promoted in 5 out of 7 services and consist of: informing the patient about his/her risk algorithm ( 3 out of 5
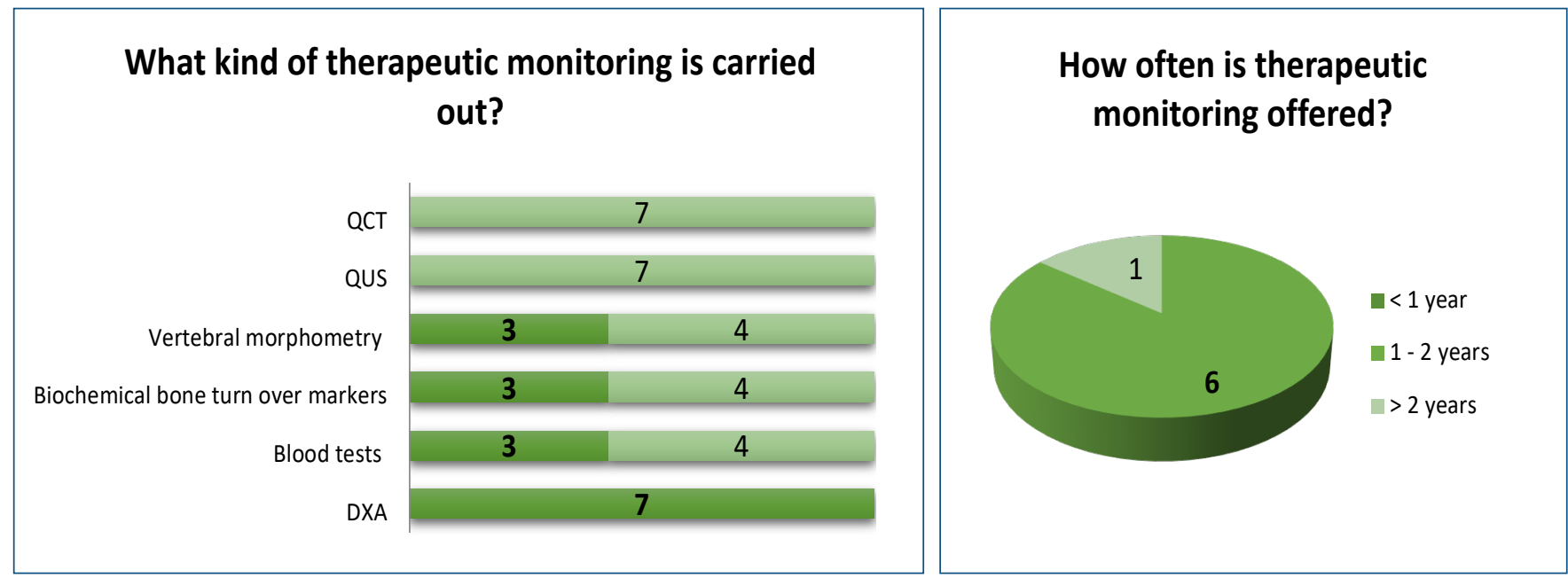

Fig. 13-14 

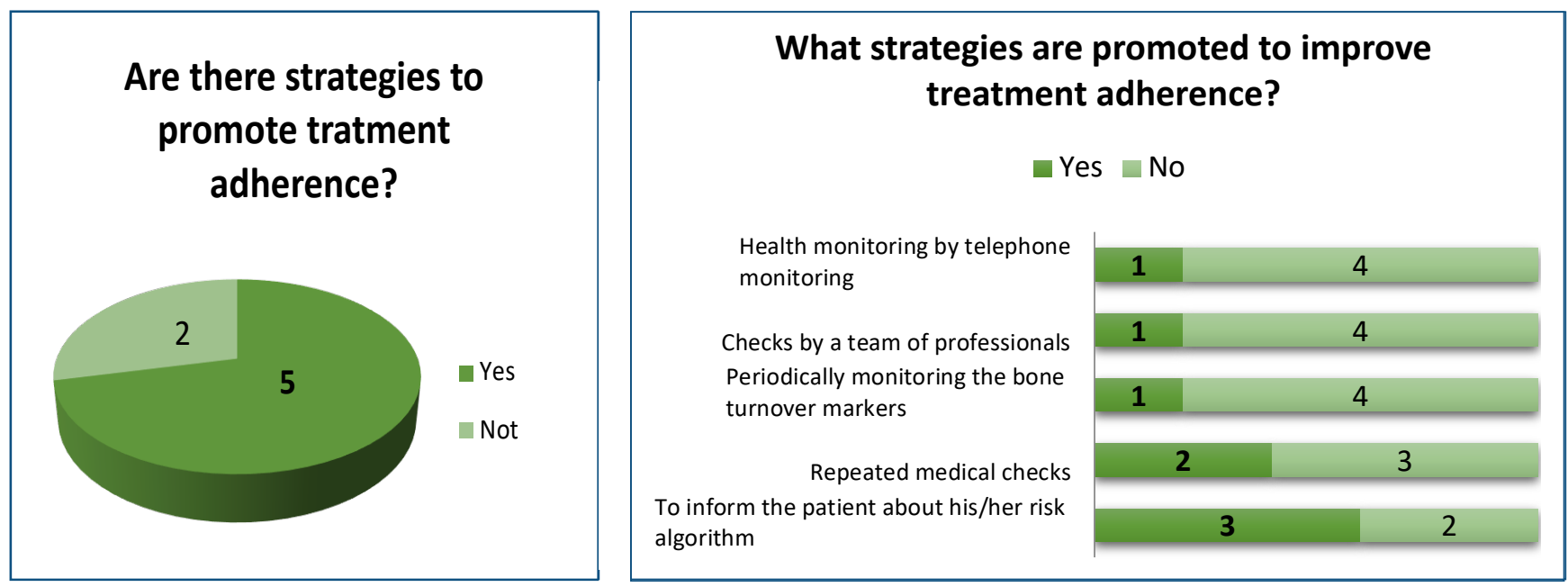

Fig. 15-16

cases), scheduling repeated medical checks (2 out of 5 services), periodically monitoring the bone turnover markers, schedule checks by a team of professionals and practice health monitoring by telephone monitoring ( 1 out of 5 cases).

Some responses agree with the indications contained in the SIOMMMS guidelines, which suggest the use of risk algorithms to give the patient a perception of their condition and to resort to monitoring bone turn over. Other answers are instead motivated by the scientific literature.

The analysis of the questionnaires received revealed several critical aspects related to taking care of the patient with fracture risk and deserving of possible improvement actions:

\begin{tabular}{|c|c|}
\hline Critical aspects & Improvement actions \\
\hline Information accessibility and citizen empowerment & $\begin{array}{l}\text { Promote information and awareness campaigns. } \\
\text { Improve accessibility to information through the consulta- } \\
\text { tion of various Local Health and Hospital Authorities' up- } \\
\text { dated websites in particular referring to a detailed and clear } \\
\text { "Service Charter". } \\
\text { Emphasize the role of GP, the first health professional with } \\
\text { which the patient has relationship. }\end{array}$ \\
\hline $\begin{array}{c}\text { Early and exhaustive interception } \\
\text { of the risky population }\end{array}$ & $\begin{array}{l}\text { Define the fracture risk by associating risk factors for osteo- } \\
\text { porosis and risk factors for falls and develop a "Profile of } \\
\text { falls" to investigate, in a multidimensional way, all the risk } \\
\text { factors that expose the subject to fracture. }\end{array}$ \\
\hline $\begin{array}{l}\text { Strengthening of non-pharmacological interven- } \\
\text { tions regarding fracture risk prevention }\end{array}$ & $\begin{array}{l}\text { Inform the patient about the modifiable risk factors for os- } \\
\text { teoporosis and falls } \\
\text { Encourage and reward virtuous behavior } \\
\text { Make conventions/collaborations between healthcare com- } \\
\text { panies and associations for the elderly / local authorities in } \\
\text { order to enhance physical activity adapted (intended for sub- } \\
\text { jects with good levels of autonomy, minimum complexity } \\
\text { and comorbidity) }\end{array}$ \\
\hline Adherence to the proposed treatments & $\begin{array}{l}\text { Give perception of illness severity to the patient } \\
\text { Carefully inform patients about taking medicines and their } \\
\text { side effects } \\
\text { Provide an available contact in case of need } \\
\text { Plan periodic clinical appointments }\end{array}$ \\
\hline
\end{tabular}

Tab. 4

\section{REFERENCES}

1. AIFA. (2014) Rapporto nazionale sull'uso dei farmaci.

2. Bliuc, D., Nguyen, N.D., Milch, V.E., \& al. (2009) Mortality risk associated with low- trauma and subsequent fracture in men and women. Jama, 301, 513-21.

3. Cree, M., Carriere, K.C., Soskolne, C.L., \& al. (2001) Functional dependance after hip fracture. Am J Phys Med Rehabil, 80, 736-43. 
4. Lindsay, Robert, \& al. (2001) Risk of new vertebral fracture in the year following a fracture. Jama, 285.3, 320-323.

5. Ministero della salute (2010). Quaderni della Salute. Appropriatezza diagnostica e terapeutica nella prevenzione delle fratture da fragilità. Luglio-Agosto 2010.

6. Papaioannou, A., Watts, N.B., Kendler, D.L., \& al. (2002) Diagnosis and management of vertebral fractures in elderly adults. Am J Med, 113, 220-8.

7. Piscitelli, Prisco, \& al. (2010) Pharmacological treatment of hip fractured patients in Italy: a simulation based on Tuscany regional database for the TARGET project. Clinical cases in mineral and bone metabolism, 7.2, 140.

8. Ross, Susan, \& al. (2011) A meta-analysis of osteoporotic fracture risk with medication nonadherence. Value in Health, 14.4, 571-581.

9. Santi, Zanoni, Cetta, (2010) Fattori determinanti l'aderenza alla terapia farmacologica per l'osteoporosi e possibili strategie per migliorarla. G Gerentol, 58, 110-116.

10. Scottish Intercollegiate Guidelines Network (SIGN). (2015). Management of osteoporosis and the prevention of fragility fractures. A national clinical guideline.

11. Sewerynek, E., Horst-Sikorska, H., Stępień-Kłos, W., Antkowiak, A., Janik, M., Cieślak, K,. Marcinkowska, M., Cegłowska, A., \& Stuss, M. (2013) The role of counselling and other factors in compliance of postmenopausal osteoporotic patients to alendronate 70 therapy. Arch Med Sci, 9(2), 288-296.

12. SIMFER. Linee Guida per il trattamento riabilitativo nell'osteoporosi postmenopausale e senile.

13. SIOMMMS. (2012). Linee Guida per la Diagnosi, Prevenzione e Terapia dell'Osteoporosi. Società italiana dell'osteoporosi, del metabolismo minerale e delle malattie dello scheletro.

14. The National Board of Health and Welfare, Stockholm, Sweden. (2005). National Board of Health and Welfare Care and services to elderly persons. 